This item was submitted to Loughborough's Research Repository by the author.

Items in Figshare are protected by copyright, with all rights reserved, unless otherwise indicated.

\title{
A visibility and total suspended dust relationship
}

PLEASE CITE THE PUBLISHED VERSION

http://dx.doi.org/10.1016/j.atmosenv.2014.02.038

\section{PUBLISHER}

(c) Elsevier Ltd

\section{VERSION}

AM (Accepted Manuscript)

\section{PUBLISHER STATEMENT}

This work is made available according to the conditions of the Creative Commons Attribution-NonCommercialNoDerivatives 4.0 International (CC BY-NC-ND 4.0) licence. Full details of this licence are available at: https://creativecommons.org/licenses/by-nc-nd/4.0/

\section{LICENCE}

CC BY-NC-ND 4.0

\section{REPOSITORY RECORD}

Baddock, Matthew C., Craig L. Strong, John Leys, S.K. Heidenreich, E.K. Tews, and Grant H. McTainsh. 2019. "A Visibility and Total Suspended Dust Relationship". figshare. https://hdl.handle.net/2134/17698. 
M.C. Baddock ${ }^{1 *}$, C.L. Strong ${ }^{1}$, J.F. Leys ${ }^{2}$, S.K. Heidenreich ${ }^{2}$, E.K. Tews ${ }^{3}$ and

${ }^{1}$ Atmospheric Environment Research Centre, Griffith School of Environment,

7 Griffith University, Brisbane, Queensland, Australia 4111

8

${ }^{2}$ Office of Environment and Heritage, Science Division, Gunnedah, New South Wales, Australia 2380

*Corresponding author

Tel: +61 737357645

Fax: +61 737354378

Email:m.baddock@griffith.edu.au

This study reports findings on observed visibility reductions and associated concentrations of mineral dust from a detailed Australian case study. An understanding of the relationship between visibility and dust concentration is of considerable utility for wind erosion and aeolian dust research because it allows visibility data, which are available from thousands of weather observation stations worldwide, to be converted into dust concentrations. Until now, this application of visibility data for wind erosion/dust studies has been constrained by the scarcity of direct measurements of co-incident dust concentration and visibility measurements. While dust concentrations are available from high volume air samplers, these time-averaged data cannot be directly correlated with instantaneous visibility records from meteorological observations. This study presents a new method for deriving instantaneous values of total suspended dust from time averaged (filter-based) samples, through reference to high resolution $\mathrm{PM}_{10}$ data. The development and testing 
of the model is presented here as well as a discussion of the derived expression in relation to other visibility-dust concentration predictive curves. The current study is significant because the visibility-dust concentration relationship produced is based on visibility observations made $10-100 \mathrm{~km}$ from the dust sources. This distance from source makes the derived relationship appropriate for a greater number of visibility recording stations than widely-used previous relationships based on observations made directly at eroding sources. Testing of the new formula performance against observed total suspended dust concentrations demonstrates that the model predicts dust concentration relatively well $\left(r^{2}=0.6\right)$ from visibility. When considered alongside previous studies, the new relationship fits into the continuum of visibility-dust concentration outcomes existing for increasing distance-fromsource. This highlights the important influence that distance to source has on the visibility-dust concentration relationship.

Keywords: duststorm; sandstorm; air quality; PM10; aerosols; TSP

\section{Introduction}

The visibility distance at the time of observation is a commonly reported atmospheric variable in meteorological data. The presence of smoke, pollution, moisture and suspended mineral dust in the atmosphere can all result in a reduction in visibility. The impact that dust has on visibility is a chief cause of the transport disruptions caused by these aeolian phenomena (Baddock et al., 2013; Tozer and Leys, 2013). For research into aeolian dust, the degree of visibility reduction associated with dust-related weather codes has provided fundamental information on the spatio-temporal characteristics of dust activity. Before the advent of satellite remote sensing, visibility was the dominant variable used in mapping the distribution of wind erosion and dust activity (Orgill and Sehmel, 1976; Middleton et al., 1986; McTainsh and Pitblado, 1987; Goudie and Middleton, 1992).

Visibility has been widely used in dust studies because these basic data are readily available from thousands of observation stations in the World Meteorological Organisation (WMO) network, and are often available for long 
69

time series. Values of the concentration of dust in the atmosphere however represent a more process relevant and precisely quantifiable measure of mineral dust loading than visibility. For instance, dust concentration is the form by which off-site air quality is measured and regulated, such as in maximum concentration for dust particles of all sizes, TSD (Total Suspended Dust), or size-selective e.g., $\mathrm{PM}_{10}$ (particles <10 $\left.\mu \mathrm{m}\right)$ (e.g., Stetler and Saxton, 1996; Neff et al., 2013).

Estimates of dust concentration can be derived from visibility measurements, and several empirical relationships that relate concentration to visibility have previously been put forward (e.g., Chepil and Woodruff, 1957; Patterson and Gillette, 1977; Ben Mohamed and Frangi, 1986; D'Almeida, 1986; Chung et al., 2003; Wang et al., 2008). Such visibility-based estimates of dust concentration have numerous applications in; the mapping of wind erosion (McTainsh et al., 2008; O'Loingsigh, 2014), the 'ground truthing' of remote sensing (Wang and Christopher, 2003; Guo et al., 2009), air quality assessments (Ozer et al., 2006; Dagsson-Waldhauserova et al., 2013), the validation of dust activity modelling (Shao et al., 2003; 2007), the estimation of peak loads of large dust storms (Raupach et al., 1994; Chung et al., 2003; McTainsh et al., 2005; Leys et al., 2011) and for better understanding the effects of suspended mineral aerosols on the radiative budget (e.g., Sokolik et al., 2001; Satheesh and Moorthy, 2005).

The various empirical expressions that relate visibility and dust concentration have been found to differ between studies (Patterson and Gillette, 1977; Ben Mohamed and Frangi, 1986; Dayan et al., 2007; Shao et al., 2007; Wang et al., 2008). For such expressions to be useful in dust-atmospheric studies, it is important that this variability be understood. Furthermore, so that accurate estimates of dust concentration can be produced from visibility, it is also important that the most appropriate expression be applied for a given visibility observation location. The need to understand the relationship between visibility and dust concentration as part of wind erosion research has long been recognised (e.g., Ette and Olorode, 1988; Ackerman and Cox, 1989; Shao et al., 2003). In particular, two classic studies in the United States, those 
103

104

105

106

107

108

109

110

111

112

113

114

115

116

117

118

119

120

121

122

123

124

125

126

127

128

129

130

131

132

133

134

135

of Chepil and Woodruff (1957) and Patterson and Gillette (1977) used

empirical fits of observed data to describe the relationship

$$
C_{m}=A / V^{\gamma}
$$

with

$$
A=C_{m} V
$$

where $C_{m}$ is total mass concentration, $A$ is a term related to the effects on extinction due to particle size distribution, $\mathrm{y}$ a constant and $V$ is observed visibility. These studies demonstrate the suitability of the power relationship in describing the relationship between visibility and dust concentration.

Patterson and Gillette (1977) noted the variety in the values of constant terms put forward to relate concentration and visibility. They attributed the lack of a single applicable term to variations in dust particle size distributions (PSD) between both dust events and study areas. PSDs can be highly variable between wind erosion episodes, and are controlled chiefly by source soil characteristics, wind erosivity and the distance of observation point from the eroding source (El-Fandy, 1953, Chepil and Woodruff, 1957).

It is noteworthy that both the Chepil and Woodruff (1957) and Patterson and Gillette (1977) studies were based on visibility and dust concentration measurements made at, or very close to, eroding sources. This constrains the application of their visibility and dust concentration functions because worldwide, the most readily available source of visibility data is from WMO meteorological stations which are impacted by dust, but are not located directly at the eroding source. An expression describing the visibility and dust concentration relationship at a greater distance from source will therefore be more appropriate for these locations. Following terminology from the transport distance model of Tsoar and Pye (1987), dust within a few kilometres from its source can be termed local, while $>10 \mathrm{~km}$ dust can be regarded as regional (see also Cattle et al., 2009). 
137 The aim of this study was to produce a relationship between visibility and total

138 suspended dust concentration for dust events observed at a regional scale

139 (10-100 km) from source. A new method is presented here for obtaining

140 instantaneous dust concentrations from time-averaged data, to allow their

141 correlation with instantaneous visibility observations.

\section{Methods}

\subsection{Background to methods}

145 The most reliable source of near-surface dust concentration data is field

146 sampling using active samplers, such as vacuum pump-based devices (e.g.,

147 Nickling and Gillies, 1993; Nickling et al. 1999), or from networks of high

148 volume samplers (HVS) (Leys et al., 2008). Such equipment however is

149 costly, labour intensive to operate and largely impractical for widespread

150 spatial monitoring of dust, especially in remote areas. A more widely

151 applicable approach for wind erosion monitoring involves the use of

152 DustTrak $^{\circledR}$ (TSI, St. Paul, MN, USA) samplers (Leys et al., 2008). DustTrak

153 instruments provide real time dust concentrations, but only for particulates

154 with an aerodynamic size of $<10 \mu \mathrm{m}\left(\mathrm{PM}_{10}\right)$. This size selectivity makes such

155 instruments suitable for monitoring air pollution and the associated effects that

156 fine particles have on human health. While $\mathrm{PM}_{10}$ is being successfully used

157 for wind erosion mapping (e.g., Wang et al., 2008), wind erosion events also

158 entrain coarser particles than this size. As a result, $\mathrm{PM}_{10}$ does not fully

159 characterise all dust events, or describe the full size range of suspended

160 particles contributing to atmospheric mass loadings (Tsoar and Pye, 1987;

161 Lawrence and Neff, 2009; Neff et al., 2013). It is preferable therefore for

162 measurements of dust concentration for a given dust event to be calculated

163 from the entire range of particle sizes present.

165 High volume samplers (HVS) collect the total range of particles in the air, but

166 as the resultant dust concentration is time-integrated over the total sampling

167 period for which the HVS was operating (generally $24 \mathrm{~h}$ ), these time-averaged

168 data have a poor relationship with time-averaged visibility. The focus of the

169 current study is to use the high resolution time series of $\mathrm{PM}_{10}$ dust 
concentration measured with a DustTrak $\left(C_{D T}\right)$ to calculate the equivalent total dust concentration measured with a co-located HVS $\left(C_{H V S}\right)$ for a point in time $\left(C_{H V S i}\right)$, which can then be correlated with the concurrent visibility. The resultant relationship is referred to from here on as the Visibility-Total Suspended Dust (V-TSD) model.

\subsection{Site and sampling details}

A HVS and a DustTrak instrument, operated by the New South Wales Office of Environment and Heritage (OEH) and Griffith University, provide two forms of dust concentration data at Buronga, New South Wales $\left(34.17^{\circ} \mathrm{S}\right.$, $\left.142.20^{\circ} \mathrm{W}\right)$. The HVS at this site constitutes the longest rural record of dust concentration in Australia, monitoring dust in the intensively cultivated Mallee region for over 24 years (Leys et al., 2008). For dust events, the HVS collects the full range of suspended particles on glass fibre filter papers (Whatman GF/A with nominal pore size of $1.6 \mu \mathrm{m}$ ) using a sampling flow rate of about $0.7 \mathrm{~m}^{3} \mathrm{~min}^{-1}$. The record of HVS dust event concentration data from Buronga was examined for the years $2004-2007$.

Determination of dust concentration from the HVS is in part governed by the duration that each filter sampled for. As filter changing is a manual operation, the sampling time varied for each filter (20-75 hours). This time period introduces the chance of multiple dust events becoming sampled. In conjunction with the HVS filter data, 5-minute $\mathrm{PM}_{10}$ data from the DustTrak at Buronga were also used in order to measure the timing and duration of the dust events.

The dust concentration data gathered at Buronga were correlated with visibility data from Mildura, Victoria as the nearest Australian Bureau of Meteorology (BoM) station, located $12 \mathrm{~km}$ to the south-west of Buronga. Visibility data from Mildura came from two datasets; the regular 3-hourly synoptic observation ( Vis $_{\text {synop }}$ ) (excluding the midnight 0000 reading) and irregular A37 visibility recordings ( $V i s_{A 37}$ ), which have a 5 to 30-minute frequency when available. A37 reports augment the synoptic record and are typically recorded during notable weather phenomena such as dust events. 
204 Whilst it would have been preferable to have the concentration sampling sited 205 at the same location as the BoM visibility observation, for practical reasons 206 this was not possible. The siting of instruments and the observer in different 207 locations creates some challenges and these were taken into account by the 208 method used for comparing visibility and dust concentration.

\subsection{Deriving instantaneous dust concentration from HVS data}

211 From the HVS filters obtained at Buronga during 2004-2007, a total of 13

212 filters was used to create a high quality dataset comprising 83 discrete dust

213 concentrations. The selection criteria producing the 13 filters included: i) TSD

214 load $>100 \mu \mathrm{g} / \mathrm{m} 3$ and filter run time between 18 and 30 hours, ii) a

215 continuous 5-minute $\mathrm{PM}_{10}$ concentration record existed for the HVS sampling

216 period, iii) the availability of high temporal resolution A37 visibility

217 observations for the dust event and iv) wind direction during the event from

218 the south west, to ensure that dust observed at Mildura was measured at

219 Buronga.

221 Given that the DustTrak is limited to recording the $\mathrm{PM}_{10}$ fraction, the ratio 222 between $\mathrm{PM}_{10} / \mathrm{TSD}$ was determined for each dust event in order to relate the 223 high frequency $\mathrm{PM}_{10}$ concentration to TSD. Calculation of this ratio involves 224 two assumptions; i) that the $\mathrm{PM}_{10}$ dust concentration time series is the same 225 as the TSD time series, and the only difference between the measurements is 226 the particle size limitation of the $\mathrm{PM}_{10}$ measurements, ii) that the $\mathrm{PM}_{10}$ to TSD 227 ratio is constant over the HVS sample period $t=0$ to $t=T$. Accepting these 228 conditions, equation 3 defines how the $\mathrm{PM}_{10} / \mathrm{TSD}$ ratio (a) relates the 229 DustTrak and HVS concentrations

$$
C_{D T_{t}}=a * C_{H V_{t}}
$$

232 where $C_{D T_{t}}$ is $\mathrm{PM}_{10}$ concentration from DustTrak, $C_{H V_{t}}$ is TSD concentration 233 from HVS, and $a$ is the ratio between the two. This ratio was determined for 234 each HVS filter paper used, or in other words, for each dust event examined. 235 
236 The total mass $m$ collected on the filter paper for any given time interval $t=0$ to $237 t=T$ is

238

$$
m=\int_{t=0}^{t=T} C_{H V_{t}} * \frac{d V}{d t} * d t
$$

239

240 Because the volume of air flow passing through the filter can be regarded as a

241 constant for each sampling event $(\dot{V}=d V / d t)$, re-arranging equations 3 and 2424 produces

$$
m=\frac{\dot{V}}{a} * \int_{t=0}^{t=T} C_{D T_{t}} * d t
$$

243

244 From the total mass on the filter for the sampling period, the total air volume 245 sampled, and the time-averaged $\mathrm{PM}_{10}$ concentration of the DustTrak $\left(\bar{C}_{D T_{t}}\right)$ for 246 the same period, the value of a can be determined through

$$
\bar{C}_{D T_{t}}=a * \bar{C}_{H V_{t}}
$$

248

249

re-arranged to

250

$$
a=\frac{C_{D T_{t}}}{m_{H V} / V_{H V}}
$$

251

As the object of the study was to relate visibility to dust concentration, an instantaneous value of TSD concentration at time $\left(C_{H V_{t}}\right.$ at time $\left.i\right)$ was required. For this, equation 8 was applied

$$
C_{H V_{i}}=\frac{C_{D T_{i}}}{a}
$$

257 To obtain $C_{H V_{i}}$, first, the measured $\mathrm{PM}_{10}$ concentration $C_{D T_{i}}$ was obtained for $i$ 258 when an A37 visibility reading existed. One issue with the split-site sampling 259 and the distance between Mildura and Buronga is the small time difference in 
260 the onset of dust between the two locations (Figure 1). As this effectively

261 represents a time lag between the sites, the time difference was calculated

262 and applied to the lagging station to ensure that $A 37$ visibilities and $P_{10}$ data

263 corresponded with one another. For instance, in Figure 1, the drop in visibility

264 marking the event onset occurred at 18:13 at Mildura, when windspeed was

$26542 \mathrm{~km} / \mathrm{h}$ and wind direction 220 $0^{\circ}$. At Buronga, downwind of Mildura and to the

$266 \mathrm{NE}$, the peak $\mathrm{PM}_{10}$ concentration was 11 minutes later, an acceptable time

267 lag given the Mildura wind data and the $12 \mathrm{~km}$ distance between the sites. Per

268 equation 8, the $\mathrm{PM}_{10}$ concentration at $i$ was divided by the $\mathrm{PM}_{10} / T S D$ ratio (a)

269 to yield an instantaneous TSD concentration for the time of the visibility

270 reading.

271

$272>>$ Figure 1 here

273

$274 \quad 2.4$ Testing the $V$-TSD model

275 In order to validate the V-TSD expression, a comparison was made between

276 values of dust concentration estimated from the model and those directly

277 measured by the HVS. From the HVS filters obtained at Buronga during 2002

278 and 2003, a total of 22 filters was used as a test database, with each one

279 representing an individual dust event. The use of this time period, which was

280 prior to the years used to develop the V-TSD model, ensured the test dataset

281 was independent of that used to formulate the model. To incorporate a range

282 of dust concentrations in the testing (i.e., different dust event intensities), of

283 the 22 events, four filters were randomly chosen from events with $C_{H V S}>300$

$284 \mu \mathrm{g} / \mathrm{m}^{3}$ to represent relatively intense dust conditions, seven filters for

285 moderate dust concentration $\left(100-300 \mu \mathrm{g} / \mathrm{m}^{3}\right)$ and eleven filters with $<100$

$286 \mu \mathrm{g} / \mathrm{m}^{3}$.

287

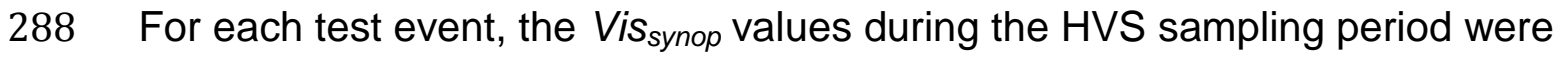

289 used to determine visibility. Given that $C_{H V S}$ represents the dust concentration

290 over the extended period that the HVS sampled, multiple three-hourly Vis synop

291 values existed for each dust event. To account for this, the V-TSD modelled

292 dust concentration was calculated for an event by substituting each visibility

293 into the V-TSD model and then weighting the result by the time period that the 
visibility represented. This was achieved through multiplication of the estimated concentration by the time interval (e.g., three hours). The timeweighted concentration values were summed and divided by total event duration to produce the modelled concentration $\left(C_{V T S D}\right)$.

\section{Results}

300 The extended duration of individual dust events typically provided multiple high-frequency A37 visibilities at different times throughout each event. Equation 8 could therefore be applied to a range of visibilities and therefore dust concentrations $(n=83)$ from the 13 events of 2004-2007. Best fitting this data produced the V-TSD model (Figure 2) represented by the relationship

$$
C_{V T S D}=4050 * V \text { is }^{-1.016}
$$

where $C_{V T S D}$ is total suspended dust concentration $\left(\mu \mathrm{g} / \mathrm{m}^{3}\right)$ and Vis is visibility $(\mathrm{km})$. The power form for the expression was adopted because comparable earlier studies produced expressions of this form, also with power functions close to 1 (Chepil and Woodruff, 1957; Patterson and Gillette, 1977; Wang et al., 2008), and the $r^{2}=0.79$ of equation 9 reveals a relatively strong correlation.

>>Figure 2 here

Section 2.4 detailed how a dataset was produced in order to test the predictive ability of the V-TSD model. When dust concentrations calculated by

318 equation 9 ( $\left.C_{V T S D}\right)$ were plotted against the measured HVS dust concentration 319 ( $\left.C_{H V S}\right)$ for 22 independent dust events from 2002-2003, a positive linear fit resulted with an $r^{2}=0.60$ (Figure 3).

>>Figure 3 here

\section{Discussion}


326 The aim of this study was to examine the relationship between TSD

327 concentration and visibility for the Mildura/Buronga location. Although the

328 correlation between TSD and visibility is relatively strong, in some sections of

329 the plot the strength of the relationship is weaker (Figure 2). Between 3 and 6

$330 \mathrm{~km}$ visibility, concentrations generated by the V-TSD model were greater than

331 the line of best fit. This is most likely a consequence of overestimation of

332 visibility by observers for this range of distance, and is exacerbated by the

333 relatively few observations at visibilities between 1 and $3 \mathrm{~km}$. For visibility

334 observations of $7 \mathrm{~km}$ and above, dust concentrations were variable, but

335 typically under $1000 \mu \mathrm{g} / \mathrm{m}^{3}$. At these distances, the variation in the recorded

336 concentration values for a given visibility must partly reflect the subjectivity of

337 visibility estimation at such range in conditions with reduced dust loading.

339 The V-TSD model is based on the consideration that it is the complete particle

340 size range of suspended dust that exerts a fuller influence on visibility (El-

341 Fandy, 1953). However, as the DustTrak instrument also provided direct

342 measurements of $\mathrm{PM}_{10}$ concentration, a useful comparison can be made

343 between the relationship of $\mathrm{PM}_{10}$ concentration with visibility, and that of TSD

344 from Figure 2. Using instantaneous $\mathrm{PM}_{10}$ concentrations in place of the

345 modeled TSD values, the weaker correlation with visibility that the size

346 selective dust concentration results in, compared to the full particle size

347 range, is evident (Figure 4$)$. In fact, the contribution that large $\left(>P M_{10}\right)$ dust

348 particles make to total dust concentrations in the Colorado Plateau region of

349 the U.S. has recently been demonstrated by Neff et al. (2013). Given the

350 relative prevalence of $\mathrm{PM}_{10}$ monitoring devices however, for instance, as part

351 of air quality monitoring networks, the relationship between visibility and the

352 concentration of dust limited to $\mathrm{PM}_{10}$ size is still of appreciable utility for wind

353 erosion studies (Chung et al., 2003; Dayan et al., 2007; Wang et al., 2008;

354 Leys et al., 2011).

355

$356>>$ Figure 4 here

3584.2 Comparison of the V-TSD model with other studies 
359 Patterson and Gillette (1977) commented that expressions for estimating dust 360 concentration from visibility would vary between studies, explaining that the

361 relative concentration of large particles exerts a strong influence on the

362 visibility-dust concentration relationship. They stated that different soil

363 conditions as well as the distance that the dusts had been transported would

364 control the proportion of large particles present to affect visibility. Further

365 insights into the nature of these controls upon the visibility-dust concentration

366 relationship can be gained by comparing the curves of previous studies with

367 the $\mathrm{V}$-TSD relationship of equation 9 (Figure 5).

>>Figure 5 here

To explain the divergence between Chepil and Woodruff's (1957) expression and that of their own work, Patterson and Gillette (1977) postulated that different soil conditions between the studies produced different dust PSDs.

374 They suggested that the drought conditions during Chepil and Woodruff's 375 (1957) monitoring period (1954 - 1955) produced more erodible soils which 376 resulted in increased dust particle size. This in turn produced higher dust 377 concentrations for a given level of visibility, an effect evident in the 378 displacement of the Chepil and Woodruff line in Figure 5. Patterson and 379 Gillette also correctly assert that the difference in these empirical relationships was not due to distance from source because sampling in both studies was conducted very close to, or directly at, the eroding surfaces. Conversely, they show that the lower dust concentrations measured in the study by Bertrand et al. (1974) arose because the dusts were sampled approximately $2000 \mathrm{~km}$ from source. While the particle size characteristics of dust have been found to relate to the particle size of the source soil (e.g. Gillette and Walker, 1977; Alfaro and Gomes, 2001) the influence that the parent soil has on the PSD of dust is strongest near to source, directly above the wind-eroded surface from where the dust is entrained (Tsoar and Pye, 1987). Furthermore, the entraining wind

391 strength has been argued to affect the PSD of dust, with the influence of this 392 factor again dominant near to source (e.g., Gillette and Walker, 1977), though 
this theory is not without challenge (see Kok, 2011). For both these factors, their influence on dust PSD would be greatest closer to entrainment because with downwind transport, larger particles preferentially settle out so differences in PSD will be reduced with distance from source (Pye, 1987).

In the present study, it is significant that the dust sampling at Mildura/Buronga was not conducted immediately 'at source'. Wind erosion mapping based on meteorological observations of dust show that the cultivated sandy soils of the Mallee region 10-100 km SW of the Mildura/Buronga site is the main source region for the examined dust events (McTainsh and Pitblado, 1987). At this distance, the PSD of sampled dust would be relatively finer than at-source due to coarser particles settling out closer to source (Tsoar and Pye, 1987). As finer particles have a greater relative influence on visibility impairment than on mass concentration, the reduction of visibility by a given dust concentration is greater at a point further from source. The differences between our V-TSD expression and those of Chepil and Woodruff (1957) and Patterson and Gillette (1977) therefore probably result more from the effect of distance-fromsource, than parent soil particle size or eroding wind conditions (Figure 5). A similar result is also seen in the work of Shao et al. (2003; also Shao and Wang, 2003). In their study, the effects of distance from source were accommodated by using two expressions of the dust concentration to visibility relationship; one for cases above a threshold visibility of $3.5 \mathrm{~km}$ (assumed to be distant dusts) and the other for below $3.5 \mathrm{~km}$ visibility (local 416 dusts).

Distance from source effects may also be demonstrated by values of $A$ (equation 2), as the term used to characterise the effects of the suspended PSD on optical extinction. Patterson and Gillette (1977) explain that $A$ should be lower for observations made at greater distance from source, again owing to the reduced contribution to visibility attenuation from larger sized particles when further from source. The findings here show good agreement with the range of $A$ values presented by Patterson and Gillette. The $A$ outcomes for measurements predominantly at eroding field sources were $5.6 \times 10^{-2} \mathrm{~g} \mathrm{~m}^{-3}$ $426 \mathrm{~km}$ in Chepil and Woodruff (1957) and $2.0 \times 10^{-2} \mathrm{~g} \mathrm{~m}^{-3} \mathrm{~km}$ for Patterson and 
427 Gillette (1977). The lower average of $A\left(4.6 \times 10^{-3} \mathrm{~g} \mathrm{~m}^{-3} \mathrm{~km}\right)$ from the current 428 study of regional erosion reflects the fact that observations were made at a 429 greater distance from source $(<-100 \mathrm{~km})$. In the case of distantly sourced 430 dust, Patterson and Gillette (1977) estimated $A=1.4 \times 10^{-3} \mathrm{~g} \mathrm{~m}^{-3} \mathrm{~km}$ for 431 observations made approximately $2000 \mathrm{~km}$ from source using data of 432 Bertrand et al. (1974). This result further reinforces the significance of 433 distance from source for expressing the effect of dust on visibility.

By adding our new visibility-dust concentration curve developed for regional dusts (i.e., dust transported and observed some 10-100 km from source) to two previous visibility-dust concentration curves from at-source (Figure 5), it is now possible to more accurately estimate dust concentration using the visibility data from a much larger number of WMO stations. Our V-TSD relationship applies to the greater proportion of stations located in regions experiencing dust transport, but not located directly at the source of dust. By enhancing our capability to estimate dust concentration away from source areas, improved concentration estimates will allow for better and more complete; mapping of wind erosion (O'Loingsigh et al., 2014), comparison of ground data with remote sensing aerosol products (e.g. MODIS Deep Blue (Ginoux et al., 2012)), validation of dust emission models, and, the estimation of peak loads of large dust storms, within the region an order of $10-100 \mathrm{~km}$ downwind from source.

In addition, the methodology demonstrated here provides a means of further expanding the suite of visibility-dust concentration curves by using HVS,

452 DustTrak and visibility data from WMO stations in other wind erosion settings.

453 For example, medium distance dust concentrations could be estimated 454 without the need to conduct dedicated field experiments of the type originally carried out by Patterson and Gillette (1977).

\section{Conclusion}

458 This study is an outcome of an ongoing, long term, synergistic dust monitoring 459 program in rural New South Wales, Australia (Leys et al., 2008; McTainsh et 460 al., 2008). The study applies a novel methodology to data from high volume 
461 sampler and DustTrak dust monitoring devices to derive instantaneous values

462 of total suspended dust concentration from time-averaged values. By relating

463 high frequency meteorological visibility reports to the derived at-a-time

464 concentrations, an empirical relationship between observed visibility and

465 measured dust concentration was produced. Whereas previous studies were

466 based on field experiments dedicated to exploring the relationship between

467 visibility and dust concentration, the current study presents an innovative way

468 of utilising existing datasets to quantify this relationship.

The new model for visibility and dust concentration from the Mildura/Buronga

471 location demonstrates the effect that distance from source has on the nature

472 of the relationship. Prominent previous studies produced expressions based

473 on observations made at, or very close to, the eroding soil source. The current

474 study, by using visibility and concentration measurements made further from

475 source $(10-100 \mathrm{~km})$ demonstrates the influence of particle size, in this case,

476 reduced particle size of the dust as a result of this regional distance from

477 source. The new visibility-dust concentration expression is therefore more

478 appropriate to visibility data from those observer stations regional to source

479 areas. This makes the expression applicable to a larger number of WMO

480 stations.

\section{Acknowledgements}

483 The authors extend thanks to Terry Koen for statistical advice and Michael

484 Case (both New South Wales Office of Environment and Heritage) for

485 changing hundreds of HVS filter papers, obtaining manually recorded visibility

486 records from the BoM and maintaining the DustTrak. We also thank the input

487 of the editor regarding an early draft of the manuscript, and the constructive

488 comments of two anonymous reviewers.

\section{References}

491 Ackerman, S.A., Cox, S.K., 1989. Surface weather observations of

492 atmospheric dust over the Southwest Summer Monsoon Region. Meteorology 493 and Atmospheric Physics 41, 19-34. 
Alfaro, S.C., Gomes, L., 2001. Modeling mineral aerosol production by wind erosion: emission intensities and aerosol size distributions in source areas. Journal of Geophysical Research 106, D16, 18075-18084.

Baddock, M.C., Strong, C.L., Murray, P.S., McTainsh, G.H., 2013. Aeolian dust as a transport hazard. Atmospheric Environment 71, 7-14.

Ben Mohamed, A., Frangi, J.-P., 1986. Results from ground-based monitoring of spectral aerosol optical thickness and horizontal extinction: some specific characteristics of dusty Sahelian atmospheres. Journal of Climate and Applied Meteorology 25, 1807-1815.

506

507

Bertrand, J., Baudet, J., Drochon, A., 1974. Importance des aerosols naturels en Afrique de L'ouest. Journal de Recherches Atmospheriques 8, 845-860.

Cattle, S.R., McTainsh, G.H., Elias, S., 2009. Æolian dust deposition rates, particle-sizes and contributions to soils along a transect in semi-arid New South Wales, Australia. Sedimentology 56, 765-783.

Chepil, W.S., Woodruff, N.P., 1957. Sedimentary characteristics of Dust Storms: II. Visibility and dust Concentration. American Journal of Science 255, 104-114.

518 Chung, Y.S., Kim, H.S., Park, K.H., Jhun, J.G., Chen, S.J., 2003. Atmospheric 519 loadings, concentrations and visibility associated with sandstorms: satellite 520 and meteorological analysis. Water, Air, and Soil Pollution: Focus 3, 21-40.

522 Dagsson-Waldhauserova, P., Arnalds, O., Olafsson, H., 2013. Long-term 523 frequency and characteristics of dust storm events in Northeast Iceland 524 (1949-2011). Atmospheric Environment 77, 117-127.

526 D'Almeida, G.A., 1986. A model for Saharan dust transport. Journal of 527 Climate and Applied Meteorology 25, 903-916. 
529 Dayan, U., Ziv, B., Shoob, T., Enzel, Y., 2008. Suspended dust over

530 southeastern Mediterranean and its relation to atmospheric circulations.

531 International Journal of Climatology 28, 915-924.

532

533 El-Fandy, M.G., 1953. On the physics of dust atmospheres. Quarterly Journal

534 of the Royal Meteorological Society 79, 284-287.

535

536 Ette, A.I.I., Olorode, D.O., 1988. The effects of the Harmattan dust on air

537 conductivity and visibility at Ibadan, Nigeria. Atmospheric Environment 22,

$538 \quad 2625-2627$.

539

540 Gillette, D.A., Walker, T.R., 1977. Characteristics of airborne particles

541 produced by wind erosion of sandy soil, High Plains of West Texas. Soil

542 Science 123, 97-110.

543

544 Ginoux, P., Prospero, J.M., Gill, T.E., Hsu, N.C., Zhao, M., 2012. Global-scale 545 attribution of anthropogenic and natural dust sources and their emission rates 546 based on MODIS Deep Blue Aerosol products. Reviews of Geophysics 50, 547 RG3005.

548

549 Goudie, A.S., Middleton, N.J., 1992. The changing frequency of dust storms 550 through time. Climatic Change 20, 197-225.

551

552 Guo, J.-P., Zhang, X.-Y., Che, H.-Z., Gong, S.-L., An, X., Cao, C.-X., Guang,

553 J., Zhang, H., Wang, Y.-Q., Zhang, X.-C., Xue, M., Li, X.-W., 2009.

554 Correlation between PM concentrations and aerosol optical depth in eastern

555 China. Atmospheric Environment 43, 5876-5886.

556

557 Kok, J.F., 2011. Does the size distribution of mineral dust aerosols depend on

558 the wind speed at emission? Atmospheric Chemistry and Physics 11, 1014955910156.

560

561 Lawrence, C.R., Neff, J.C., 2009. The contemporary physical and chemical 562 flux of 
563 aeolian dust: a synthesis of direct measurements of dust deposition. Chemical

564 Geology 267, 46-63.

565

566 Leys, J., McTainsh, G., Strong, C., Heidenreich, S., Biesaga, K., 2008.

567 DustWatch: using community networks to improve wind erosion monitoring in

568 Australia. Earth Surface Processes and Landforms 33, 1912-1926.

569

570 Leys, J.F., Heidenreich, S.K., Strong, C.L., McTainsh, G.H., Quigley, S., 2011.

$571 \mathrm{PM}_{10}$ concentrations and mass transport during "Red Dawn" - Sydney 23

572 September 2009. Aeolian Research 3, 327-342.

573

574 McTainsh, G.H., Pitblado, J.R., 1987. Dust storms and related phenomena

575 measured from meteorological records in Australia. Earth Surface Processes

576 and Landforms 12, 415-424.

577

578 McTainsh, G., Chan, Y.-C., McGowan, H., Leys, J., Tews, K., 2005. The 23rd

579 October 2002 dust storm in eastern Australia: characteristics and

580 meteorological conditions. Atmospheric Environment 39, 1227-1236

581

582 McTainsh, G., Leys, J., Tews, K., Strong, C., 2008. Dust Storm Index to Dust

583 Concentration: Developing a new measure of wind erosion for national and

584 state scale monitoring. Final Report and User Guide. Griffith University,

585 Brisbane, pp. 32.

586

587 Middleton, N. J., Goudie, A.S., Wells, G.L., 1986. The frequency and

588 source areas of dust storms. In Aeolian Geomorphology, edited by W. G.

589 Nickling, pp. 237-259, Allen \& Unwin, Boston.

590

591 Neff, J.C., Reynolds, R.L., Munson, S.M., Fernandez, D., Belnap, J., 2013.

592 The role of dust storms in total atmospheric particle concentrations at two

593 sites in the western U.S. Journal of Geophysical Research 118, 11201-11212.

594

595 Nickling, W.G., Gillies, J.A., 1993. Dust emission and transport in Mali, West

596 Africa. Sedimentology 40, 859-868. 
598 Nickling, W.G., McTainsh, G.H., Leys, J.E., 1999. Dust emissions from the

599 Channel Country of western Queensland, Australia. Zeitschrift fur

600 Geomorphologie N.F. 116, 1-17.

601

602 Orgill, M.M., Sehmel, G.A., 1976. Frequency and diurnal variations of dust

603 storms in the contiguous USA. Atmospheric Environment 10, 813-825.

604

605 Ozer, P., Laghdaf, M.B.O.M., Lemine, S.O.M., Gassani, J., 2006. Estimation 606 of air

607 quality degradation due to Saharan dust at Nouakchott, Mauritania, from

608 horizontal visibility data. Water Air and Soil Pollution 178, 79-87.

609

610 Patterson, E.M., Gillette, D.A., 1977. Measurements of visibility vs mass of

611 airborne soil particles. Atmospheric Environment 11, 193-196.

612

613 Pye, K., 1987. Aeolian Dust and Dust Deposits. Academic Press, London.

614

615 Raupach, M.R., McTainsh, G.H., Leys, J.F., 1994. Estimates of dust mass in

616 recent major dust storms. Australian Journal of Soil and Water Conservation

617 7, 20-24.

618

619 Satheesh, S. K., Moorthy, K. K., 2005. Radiative effects of natural aerosols.

620 Atmospheric Environment 39, 2089-2110.

621

622 Shao, Y., Wang, J., 2003. A climatology of northeast Asian dust events.

623 Meteorologische Zeitschrift 12, 187-196.

624

625 Shao, Y., Yang, Y., Wang, J., Song, Z., Leslie, L.M., Dong, C., Zhang, Z., Lin, 626 Z., Kanai, Y., Yabuki, S., Chun, Y., 2003. Northeastern Asian dust: Real-time

627 numerical prediction and validation. Journal of Geophysical Research 108,

628 D22, 4691.

629

630 Shao, Y., Leys, J.F., McTainsh, G.H., Tews, K., 2007. Numerical simulation of 
631 the October 2002 dust event in Australia. Journal of Geophysical Research 632112, D08207.

633

634 Sokolik, I. N., Winker, D.M., Bergametti, G., Gillette, D.A., Carmichael, G.,

635 Kaufman, Y.G., Gomes, L., Schuetz, L., Penner, J.E., 2001. Introduction to 636 special section: Outstanding problems in quantifying the radiative impacts of 637 mineral dust. Journal of Geophysical Research 106, 18015-18027.

638

639 Stetler, L.E., Saxton, K.E., 1996. Wind erosion and $\mathrm{PM}_{10}$ emissions from 640 agricultural fields on the Columbia Plateau. Earth Surface Processes and 641 Landforms 21, 673-685.

642

643 Tsoar, H., Pye, K., 1987. Dust transport and the question of desert loess 644 formation. Sedimentology 34, 139-153.

645

646 Tozer, P. R., Leys, J., 2013. Dust storms - What do they really cost? The 647 Rangeland Journal 35, 131-142.

648

649 Wang, J., Christopher, S.A., 2003. Intercomparison between satellite-derived 650 aerosol

651 optical thickness and PM2.5 mass: implications for air quality studies.

652 Geophysical Research Letters 30, 2095.

653

654 Wang, Y.Q., Zhang, X.Y., Gong, S.L., Zhou, C.H., Hu, X.Q., Liu, H.L., Niu, T., 655 Yang, Y.Q., 2008. Surface observation of sand and dust storm in East Asia 656 and its application to CUACE/Dust. Atmospheric Chemistry and Physics 8, $657 \quad 545-553$.

658

659

660

661

662

663

664 


\section{Figure Captions}

667

668 Figure 1: The 5-minute $\mathrm{PM}_{10}$ dust concentration record from the DustTrak at

669 Buronga and visibility (A37 records) at Mildura for the dust event of December

$67012^{\text {th }} 2005$. Note inverted visibility on secondary vertical axis. Dashed lines

671 mark the onset of the event as detected by each monitoring technique. The

672 displacement of the plots arises because the dust event reached Mildura

673 before Buronga (see Section 2.3).

674

675 Figure 2: The relationship between visibility and total suspended dust for the

676 Mildura/Buronga sampling location, expressed as the V-TSD model $(n=83)$.

677

678 Figure 3: Measured total suspended dust concentration by HVS ( $\left.C_{H V S}\right)$ and

679 modelled total suspended dust concentration by V-TSD $\left(C_{V T S D}\right)$ for 22 dust

680 events experienced at Buronga, NSW during 2002-03 (see Section 2.4).

681

682 Figure 4: The relationship between visibility and $\mathrm{PM}_{10}$ dust for the

683 Mildura/Buronga sampling location $(n=83)$.

684

685 Figure 5: Comparison between the V-TSD model and other selected

686 expressions relating dust concentration and visibility, from Chepil and

687 Woodruff (1957) (C\&W) and Patterson and Gillette (1977) (P\&G).

688

689

690

691

692

693

694

695

696

697 


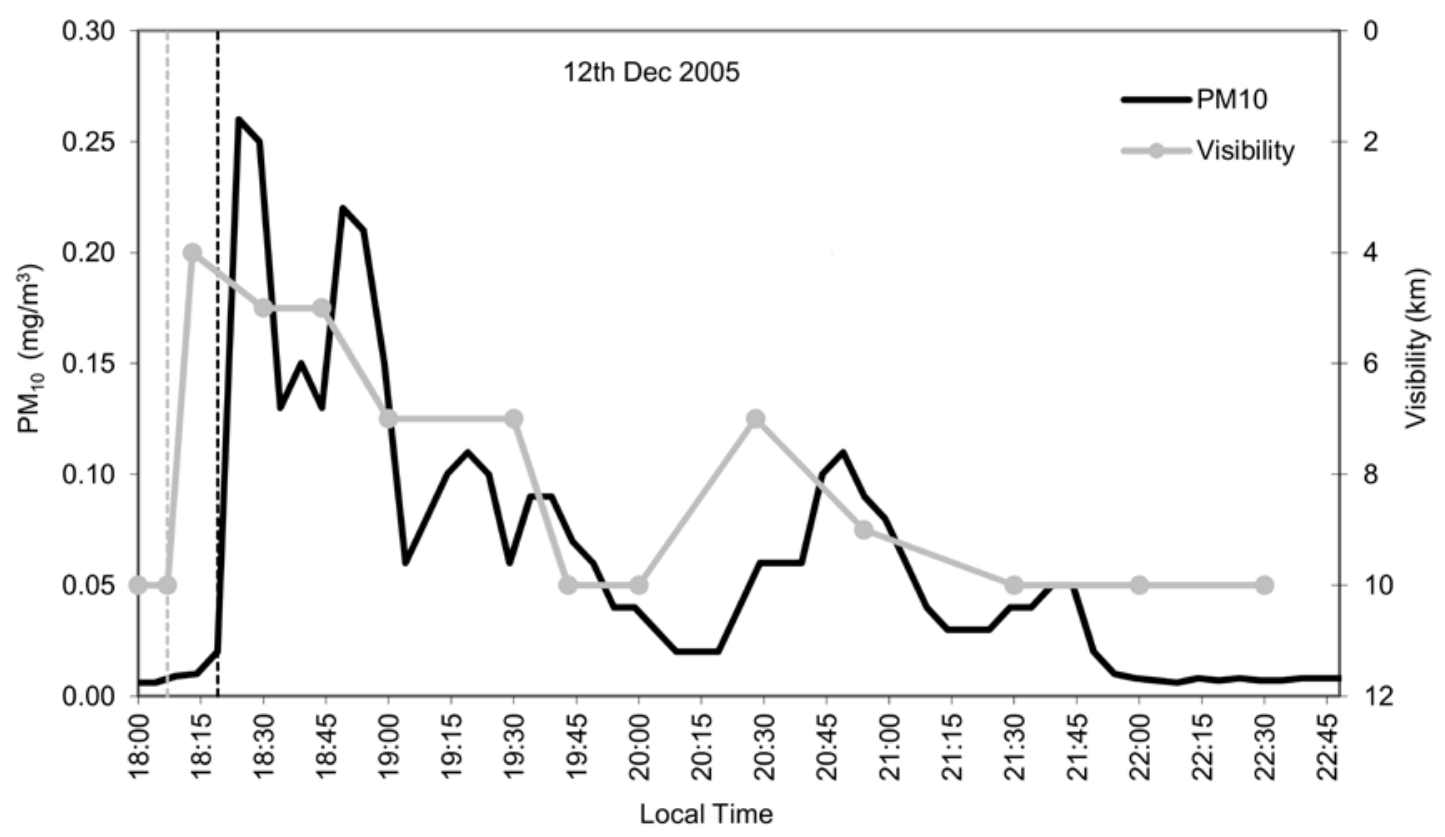

698

699 Figure 1

700

701

702

703

704

705

706

707

708

709

710

711

712

713

714

715

716

717

718

719 


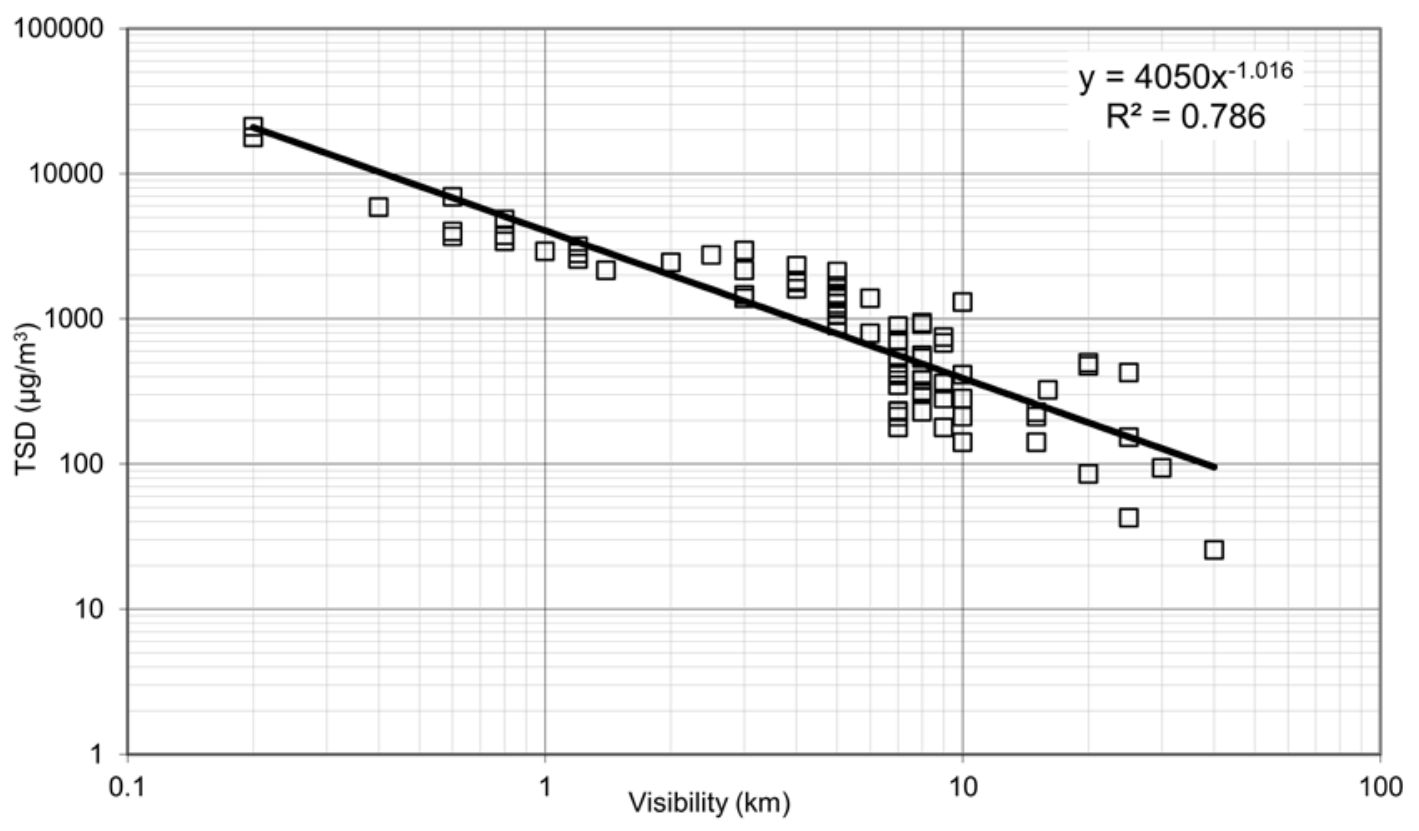

721 Figure 2

722

723

724

725

726

727

728

729

730

731

732

733

734

735

736

737

738

739

740

741 


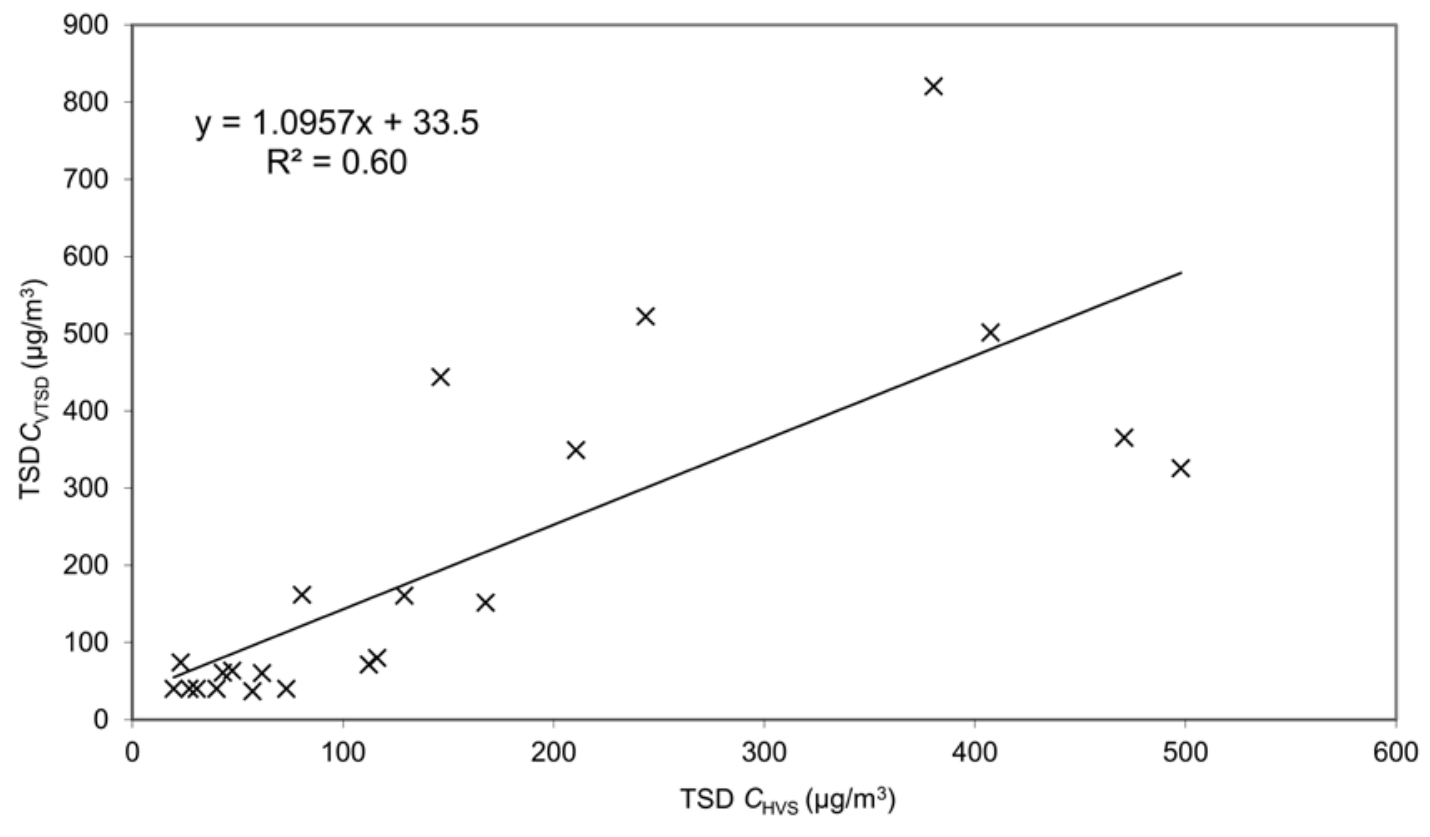

742

743 Figure 3

744

745

746

747

748

749

750

751

752

753

754

755

756

757

758

759

760

761

762

763 


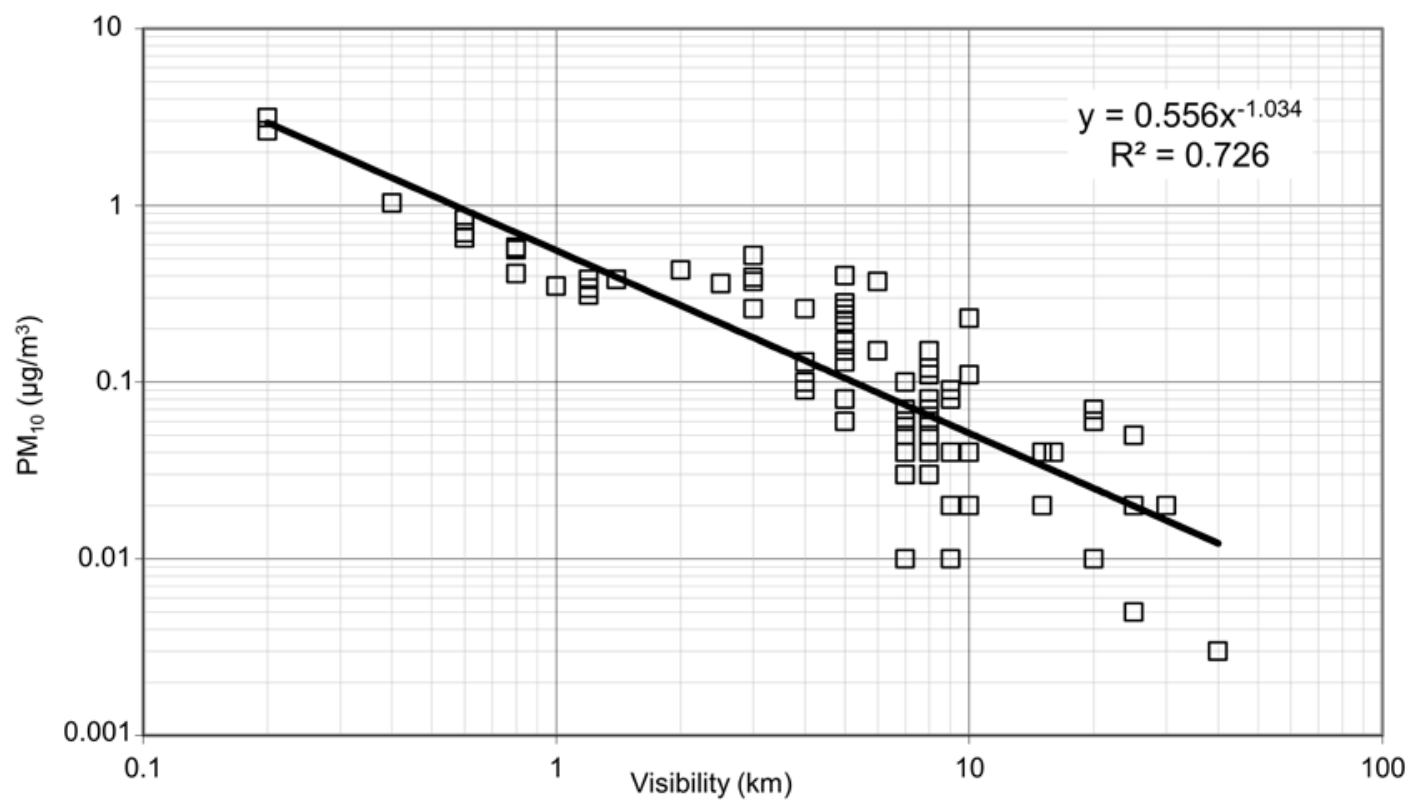

764

765 Figure 4

766

767

768

769

770

771

772

773

774

775

776

777

778

779

780

781

782

783

784

785 
786

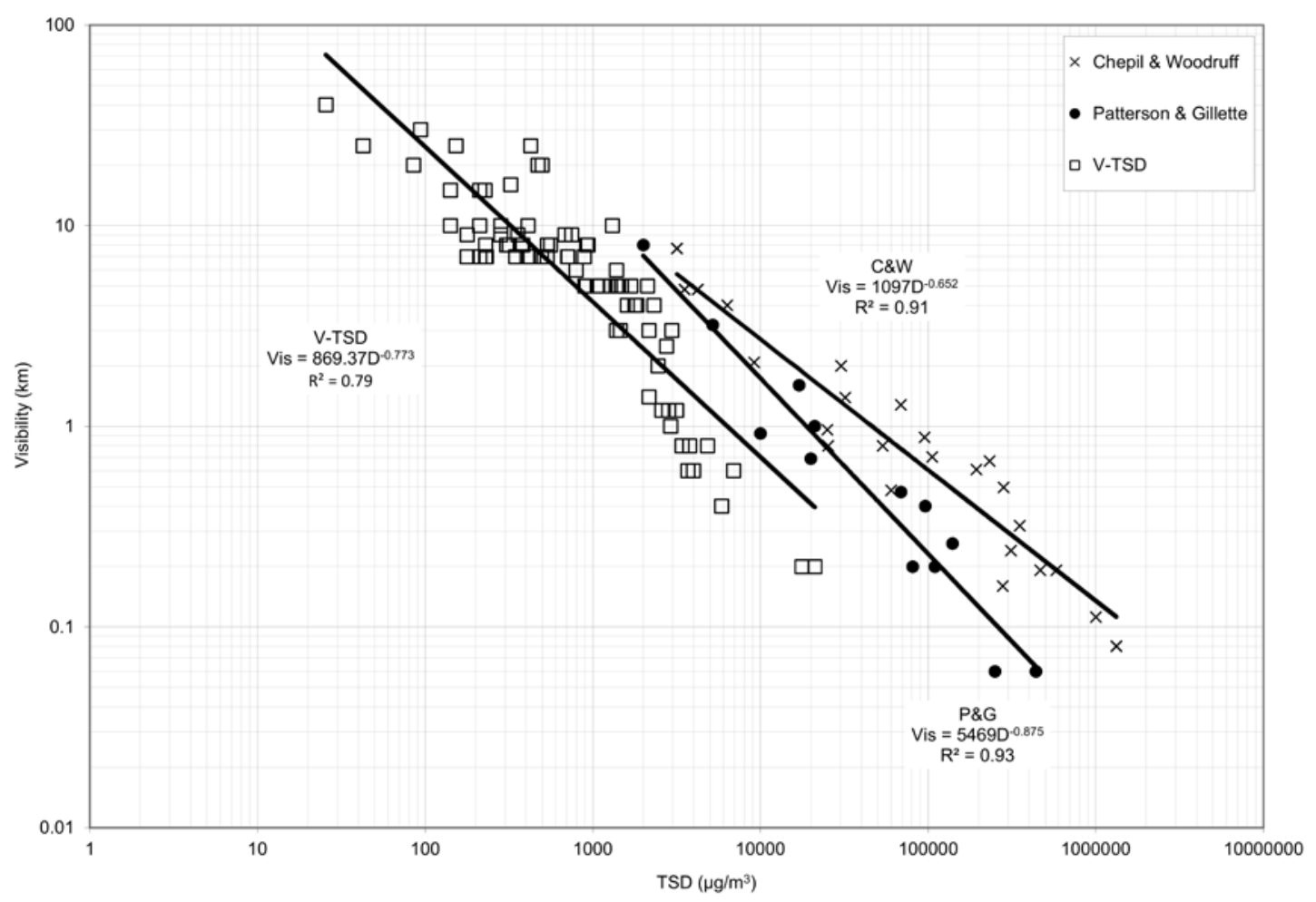

$787 \quad$ Figure 5 